\title{
Surface Modification of Cellulose Fibres
}

\author{
Mohamed Naceur Belgacem \\ Ecole Française de Papeterie et des Industries Graphiques, France \\ Alessandro Gandini
Instituto de Química de São Carlos, USP
}

\begin{abstract}
Several approaches to the modification of cellulose fibres are described, namely: (i) physical treatments such as corona or plasma treatments under different atmospheres; (ii) grafting with hydrophobic molecules using well-known sizing compounds; (iii) grafting with bi-functional molecules, leaving one of the functions available for further exploitation; and (iv) grafting with organometallic compounds. The modified surfaces were characterized by elemental analysis, contact angle measurements, inverse gas chromatography, X-ray photoelectron and infrared spectroscopy, wettability, etc. These different tools provided clear-cut evidence of the occurrence of chemical reactions between the grafting agent used and the hydroxy functions of the cellulose surface, as well as of the existence of covalent bonding in the ensuing composite materials between the matrix and the fibres through the use of doubly reactive coupling agents.
\end{abstract}

Keywords: Cellulose fibres, surface treatment, chemical grafting, surface characterisation.

\section{Introduction}

The use of natural cellulose fibres as reinforcing elements in macromolecular composite materials has recently gained considerable attention, as emphasized by the numerous reviews on the topic ${ }^{[1-7]}$. In fact, whereas glass fibre-based composites cannot be recycled at the end of their life cycle, their homologues based on fully organic components permit such an operation to be conducted, either by recycling (thermoplastic matrices) or through energy recovery (combustion of thermoset composites). In addition, despite a Young modulus which is 2 to 3 times lower than that of glass fibres, cellulose fibres possess several notable advantages, namely: (i) low density (which makes it possible to obtain lighter composites); (ii) biorenewable character; (iii) ubiquitous availability at low cost and in a variety of forms (wood, annual plants, agricultural residues, etc.); and (iv) modest abrasivity, which ensures greater longevity of the composite processing tools.

However, lignocellulosic fibres also display some limitations with respect to the present context, since they are highly polar and hydrophilic making them both poorly compatible with commonly used non-polar matrices, such as polyolefins, and subject to a loss of mechanical properties upon atmospheric moisture adsorption (e.g. from the open end of a sectioned piece of composite material). For these reasons, they are generally submitted to specific surface modifications in order (i) to provide an efficient hydrophobic barrier and (ii) to minimise their interfacial energy with the often non-polar polymer matrix and thus generate optimum adhesion.

The aim of this presentation is to provide a broad outlook of the different approaches used to treat the surface of cellulose fibres with the specific purpose of their subsequent incorporation into polymer matrices.

\section{Experimental}

A wide variety of cellulose substrates have been used for these modifications, including (i) lignocellulosic fibres from numerous wood and annual plants, used as such or after different pre-treatments, (ii) cellulose fibres obtained from the latter natural sources by delignification and bleaching, (iii) solution-regenerated continuous fibres with a regular diameter, (iv) cellophane films, (v) semi-crystalline powders like Avicell, (vi) paper sheets from different pulps and different processes (e.g. additive-free tracing paper), and (vii) filter papers made of "pure" cellulose.

Numerous families of coupling agents were used, namely: (i) fatty acid-like structures, (ii) molecules with two different reactive functions, (iii) reagents with two identical functions, and (iv) organometallic compounds.

The various characterisation techniques utilised to assess the occurrence and the extent of the modification include FTIR and XPS spectroscopy, elemental analysis, contact angle measurements, inverse gas chromatography (IGC) and scanning electron microscopy, as well as, of course, the comparison of the mechanical performance of the ensuing composites, prepared with treated and untreated fibres.

\section{Results and Discussion}

The results are divided into three different sections, according to the nature of the modification. 
Table 1. ESCA analyses of several lignocellulosic materials, before and after extraction with various solvents.

\begin{tabular}{|c|c|c|c|c|c|c|}
\hline \multirow{3}{*}{ Substrate } & \multirow{3}{*}{ Extraction Solvent } & \multirow{3}{*}{$\mathrm{O} / \mathrm{C}$} & \multicolumn{3}{|c|}{ Binding energy (eV) } & \multirow{3}{*}{ Ref. } \\
\hline & & & $\mathrm{C} 1(\mathrm{C})$ & $\mathrm{C} 2(\mathrm{C}-\mathrm{O})$ & $\mathrm{C} 3(\mathrm{O}-\mathrm{C}-\mathrm{O})$ & \\
\hline & & & 285.0 & 286.7 & 288.3 & \\
\hline \multirow{5}{*}{$\begin{array}{c}\text { Newsprint } \\
\text { commercial paper }\end{array}$} & None & 0.45 & 43 & 50 & 7 & [8] \\
\hline & Ether & 0.60 & 25 & 65 & 10 & [8] \\
\hline & Ether, acetone & 0.64 & 23 & 68 & 11 & [8] \\
\hline & Ether, acetone, water & 0.62 & 22 & 68 & 9 & [8] \\
\hline & Acetone & 0.61 & 23 & 67 & 10 & [8] \\
\hline \multirow{5}{*}{$\begin{array}{c}\text { Newsprint } \\
\text { commercial paper }\end{array}$} & None & 0.50 & 36 & 57 & 8 & [8] \\
\hline & Ether & 0.58 & 23 & 66 & 11 & [8] \\
\hline & Ether, acetone & 0.63 & 22 & 66 & 12 & [8] \\
\hline & Ether, acetone, water & 0.56 & 28 & 62 & 10 & [8] \\
\hline & Acetone & 0.64 & 22 & 64 & 14 & [8] \\
\hline \multirow{5}{*}{$\begin{array}{l}\text { Micro-crystalline } \\
\text { cellulose (Avicel) }\end{array}$} & None & 0.66 & 27.4 & 64.5 & 8.1 & {$[9,10]$} \\
\hline & Acetone & 0.80 & 15.8 & 71.5 & 12.7 & {$[9,10]$} \\
\hline & Ether & 0.78 & 18.2 & 70.8 & 11.0 & {$[9,10]$} \\
\hline & Cold water & 0.66 & 27.2 & 64.6 & 8.2 & {$[9,10]$} \\
\hline & Hot water & 0.66 & 25.1 & 65.6 & 9.3 & {$[9,10]$} \\
\hline
\end{tabular}

\section{Physical treatments}

This section includes mainly the use of solvent extraction of different substrate in order to remove any impurities or natural contaminants from the cellulose substrates. A selection of the most relevant results related to the ESCA analyses of the purified surfaces, is given in Table $1^{[8-10]}$. More details about other contributions to this field, as well as about the changes observed in the surface energy of the purified surfaces are given in a recent review ${ }^{[11]}$.

The most relevant feature related to these treatments, as shown by the data in Table 1, is the removal of surface contaminations or natural coatings richer in carbon than cellulose, i.e., waxy compounds. This "cleaning" is best achieved with a good solvent for such non-polar structures, $v i z$. acetone or ether, whereas water, as expected, fails at this task. Given the nature of these studies, the term "modification", applied to these treatments, is somewhat abusive and "purification" seems more adequate.

\section{Physico-chemical treatments}

This section covers Corona, Plasma, Laser, vacuumultraviolet and $\gamma$-ray treatments. The cellulose surface was modified according to the atmosphere in which these treatments were carried out. Here too, only some results on the surface changes, as determined by XPS analyses and IGC measurements, are given in Table $2^{[9,10,12]}$.

In these investigations, the nature of the surface modifications is highly dependent on the species generated in the gas phase, but the control of both the qualitative and quantitative moieties appended on the fibres remains a difficult task. For a more detailed discussion of this topic, the reader is again invited to consult the recent review mentioned above ${ }^{[1]}$.

\section{Chemical grafting}

This section deals with the majority of the studies in this field and is subdivided in terms of the specific approach adopted for the modification, although all of them involve the intervention of the hydroxy moieties present at the surface of the cellulose fibres. The media used for all these reactions were such that no swelling of the fibres occurred and therefore only their superficial $\mathrm{OH}$ functions were involved in the couplings.

\section{Surface compatibilisation}

This approach deals with simple coupling reactions between the surface $\mathrm{OH}$ groups of the cellulose fibres and molecular or macromolecular agents bearing one or several 
Table 2. XPS analyses and IGC data of several lignocellulosic materials, before and after different physico-chemical treatments.

\begin{tabular}{|c|c|c|c|c|c|c|c|}
\hline \multirow{3}{*}{ Substrate } & \multirow{3}{*}{ Treatment } & \multirow{3}{*}{$\mathrm{O} / \mathrm{C}$} & \multicolumn{4}{|c|}{ Binding energy (eV) } & \multirow{3}{*}{ Ref. } \\
\hline & & & C1 (C) & $\mathrm{C} 2(\mathrm{C}-\mathrm{O})$ & C3 (O-C-O) & $\mathrm{C} 4(\mathrm{O}-\mathrm{C}=\mathrm{O})$ & \\
\hline & & & 285.0 & 286.7 & 288.3 & 290.6 & \\
\hline \multirow{2}{*}{ Avicel } & None & 0.66 & 27.4 & 64.5 & 8.1 & - & {$[9,10]$} \\
\hline & Corona $40 \mathrm{~mA}$ & 0.90 & 15.4 & 64.4 & 16.8 & 3.4 & {$[9,10]$} \\
\hline \multirow{4}{*}{ Wood fibres } & $\begin{array}{c}\text { Plasma } \\
\text { (MMA } 15 \text { s) }\end{array}$ & 0.60 & 39.7 & 42.9 & 13.9 & 13.9 & {$[12]$} \\
\hline & $\begin{array}{c}\text { Plasma } \\
(\mathrm{MMA}, 15 \mathrm{~s})\end{array}$ & 0.69 & 4.1 & 74.8 & 15.3 & 5.8 & [12] \\
\hline & & & $\mathrm{C} 1(\mathrm{C})$ & $\mathrm{C} 1{ }^{\prime}(\mathrm{C}-\mathrm{N})$ & $\begin{array}{l}\mathrm{C} 2(\mathrm{C}-\mathrm{O} \\
\text { or } \mathrm{C}=\mathrm{N})\end{array}$ & $\begin{array}{l}\mathrm{C} 3(\mathrm{O}-\mathrm{C}-\mathrm{O} \\
\text { or } \mathrm{N}-\mathrm{C}-\mathrm{O})\end{array}$ & \\
\hline & & & 285.0 & 285.8 & 286.7 & 288.6 & \\
\hline \multirow{7}{*}{ Wood fibres } & None & 0.77 & 7.2 & - & 78.0 & 14.8 & [12] \\
\hline & Plasma $\left(\mathrm{N}_{2}, 15 \mathrm{~s}\right)$ & 0.62 & 14.6 & 14.1 & 56.2 & 15.1 & [12] \\
\hline & Plasma $\left(\mathrm{N}_{2}, 60 \mathrm{~s}\right)$ & 0.72 & 6.1 & 8.3 & 17.4 & 6.2 & [12] \\
\hline & Plasma $\left(\mathrm{NH}_{3}, 15 \mathrm{~s}\right)$ & 0.58 & 19.2 & 21.4 & 47.4 & 12.0 & [12] \\
\hline & Plasma $\left(\mathrm{NH}_{3}, 15 \mathrm{~s}\right)$ & 0.74 & 4.4 & 6.1 & 74.2 & 15.3 & [12] \\
\hline & & \multicolumn{5}{|c|}{ Surface energy, as calculated from IGC data } & \\
\hline & & & & $\mathrm{K}_{\mathrm{A}}$ & $\mathrm{K}_{\mathrm{D}}$ & $\mathrm{K}_{\mathrm{D}} / \mathrm{K}_{\mathrm{A}}$ & \\
\hline \multirow{2}{*}{ Avicel } & None & & & - & - & 3.0 & {$[9,10]$} \\
\hline & Corona 15 mA, & & & - & - & 3.3 & {$[9,10]$} \\
\hline \multirow{4}{*}{ Wood fibres } & None & & & 0.25 & 0.23 & 0.93 & [12] \\
\hline & Plasma $\left(\mathrm{N}_{2}, 15 \mathrm{~s}\right)$ & & & 0.16 & 0.30 & 1.80 & [12] \\
\hline & Plasma $\left(\mathrm{NH}_{3}, 15 \mathrm{~s}\right)$ & & & 0.09 & 0.31 & 3.43 & [12] \\
\hline & Plasma (MMA, 60s) & & & 0.39 & 0.1 & 0.25 & [12] \\
\hline
\end{tabular}

OH-reactive functions, either as a single terminal moiety, or as numerous moieties placed along a polymer chain. The changes observed at the surface of the treated materials are summarised very briefly in Table 3. Structures I-VII are good examples of this strategy.<smiles>[R]C=C1OC(=O)C1[R]</smiles>

$\mathrm{R}=$ long aliphatic chains

I

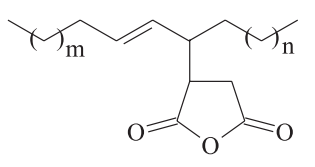

$$
\mathrm{m}+\mathrm{n}=10-11
$$

II

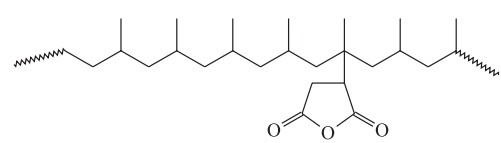

IV

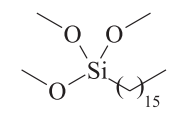

III $\mathrm{n}=2,7$ and 17

V
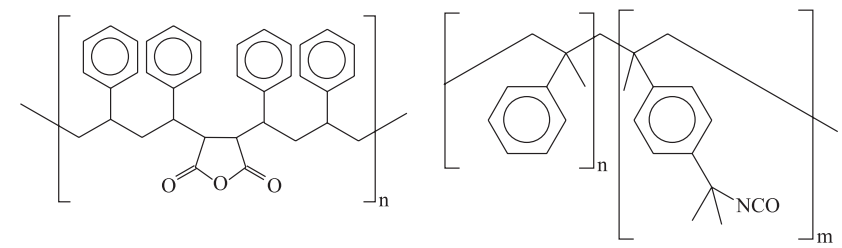

VI

The data given in Table 3 clearly prove the occurrence of the grafting, since the polar component of the surface energy of the lignocellulosic materials studied decreased drastically and the ESCA analyses indicated a substantial enrichment in carbon atoms arising from the presence of superficial methylene and/or methyl groups. Of course, in the studies reported here, the treated material was thoroughly extracted after the grafting reactions, in order to remove all unbound reagents. 
Table 3. Surface energies of lignocellulosic substrates, before and after grafting with different compatibilising agents.

\begin{tabular}{|c|c|c|c|c|c|}
\hline \multirow{2}{*}{ Material } & \multirow{2}{*}{ Grafting agent } & \multicolumn{3}{|c|}{ Surface properties $\left(\mathbf{m} \mathbf{J} / \mathbf{m}^{2}\right)$} & \multirow{2}{*}{ Ref. } \\
\hline & & $\gamma^{\mathrm{D}}$ & $\mathrm{W}^{\mathrm{AB}}\left(\mathrm{CHCl}_{3}\right)$ & $\mathrm{W}^{\mathrm{AB}}\left(\left(\mathrm{C}_{2} \mathrm{H}_{5}\right)_{2} \mathrm{O}\right)$ & \\
\hline \multirow{3}{*}{ BKP } & None & 38.3 & 2.4 & 11.2 & [13] \\
\hline & Structure I & 33.3 & 5.6 & 7.1 & [13] \\
\hline & & $\gamma^{\mathrm{D}}$ & $\begin{array}{c}\mathrm{W}^{\mathrm{AB}} \\
\text { (formamide) }\end{array}$ & $\begin{array}{c}\mathrm{W}^{\mathrm{AB}} \\
\text { (glycerol) }\end{array}$ & \\
\hline \multirow{4}{*}{ BKP } & None & 38.5 & 105.4 & 114.5 & [14] \\
\hline & Structure I & 24.9 & 44.0 & 56.7 & [14] \\
\hline & Structure II & 28.8 & 50.3 & 72.4 & [14] \\
\hline & & $\gamma^{\mathrm{D}}$ & $\gamma^{P}$ & $\gamma^{\mathrm{T}}$ & \\
\hline \multirow{4}{*}{$\alpha$ cellulose } & None & 25.5 & 43.2 & 68.7 & [15] \\
\hline & Structure II & 28.0 & 21.8 & 49.8 & [15] \\
\hline & Structure IV (low Mw) & 31.6 & 8.4 & 40.0 & [15] \\
\hline & Structure IV (high Mw) & 32.0 & 4.9 & 36.9 & [15] \\
\hline \multirow{4}{*}{$\begin{array}{l}\text { Additive-free } \\
\text { unzized } \\
\text { tracing paper }\end{array}$} & None & 29.4 & 20.0 & 49.4 & [16] \\
\hline & Structure II & 27.3 & 8.6 & 35.9 & [16] \\
\hline & Structure VI & 36.0 & 6.1 & 42.1 & [16] \\
\hline & Structure VII & 34.4 & 1.0 & 35.4 & [16] \\
\hline \multirow{2}{*}{$\begin{array}{l}\text { Technocel } \\
\text { fibres }\end{array}$} & None & 30.0 & 20.0 & 50.0 & [17] \\
\hline & Structure III & 37.0 & 0.5 & 37.5 & [17] \\
\hline
\end{tabular}

\begin{tabular}{|c|c|c|c|c|c|c|}
\hline & & \multicolumn{4}{|c|}{ Elemental surface compositions, \% } & \\
\hline & & $\mathrm{O} / \mathrm{C}$ & $\mathrm{C}$ & $\mathrm{O}$ & $\mathrm{Si}$ & \\
\hline \multirow{3}{*}{$\begin{array}{l}\text { Recycled } \\
\text { newsprint }\end{array}$} & None & 0.59 & 60.7 & 35.6 & 3.7 & {$[18]$} \\
\hline & Structure III & 0.29 & 68.7 & 19.8 & 14.3 & [18] \\
\hline & & $\mathrm{C} 1$ & $\mathrm{C} 2$ & $\mathrm{C} 3$ & $\mathrm{C} 4$ & \\
\hline \multirow{2}{*}{$\begin{array}{l}\text { Recycled } \\
\text { newsprint }\end{array}$} & None & 48.6 & 43.5 & 7.9 & - & [18] \\
\hline & Structure III & 86.7 & 8.7 & 4.6 & - & [18] \\
\hline \multirow{3}{*}{$\begin{array}{l}\text { Thermo- } \\
\text { Mechanical } \\
\text { pulps }\end{array}$} & None & 70.2 & 20.2 & 6.3 & 3.3 & [19] \\
\hline & Structure IV (low Acid Number) & 84.8 & 9.5 & 3.8 & 1.9 & [19] \\
\hline & Structure IV (high Acid Number) & 89.9 & 7.2 & 2.5 & 0.4 & [19] \\
\hline
\end{tabular}

$\mathrm{BKP}=$ bleached kraft pulps

\section{Co-polymerisation}

This strategy calls upon three sub-strategies, as described below.

\section{Grafting with polymerisable molecules}

This approach involves the use of reagents of small molecular size, bearing two functions, one capable of reacting with the superficial cellulose $\mathrm{OH}$ groups and the other employed as a source of subsequent covalent linkage with the matrix macromolecules, when processing the corresponding composite material. Structures VIII-XIII are examples of the reagents used in this context. This approach is well adapted to matrices obtained either by polyaddition polymerisation, (e.g., 
vinylic, and acrylic polymers) or polycondensation reaction (e.g., epoxy resins). Table 4 gives some of the most relevant data concerning the changes in the surface properties after the first and the second grafting steps for un-sized additive-free tracing paper substrates. These results show that the surface energy of the modified substrate becomes close to that of the grafted polymer (polystyrene or polymethyl methacrylate), which proves the success of the double grafting procedure.

The additional interest of this approach is that it can be carried out as a one-pot procedure, i.e. the first reaction takes place using the matrix monomer as the medium for the suspended fibres, which is then polymerised to construct the composite. This eliminates the need for a solvent and all the<smiles>C=C(C)C(=O)OCCN=O</smiles><smiles>CCO[Si](CCCN)(OCC)OCC</smiles>

IX<smiles>C=C(C)C(=O)OCCC[Si](OC)(OC)OC</smiles>
XI
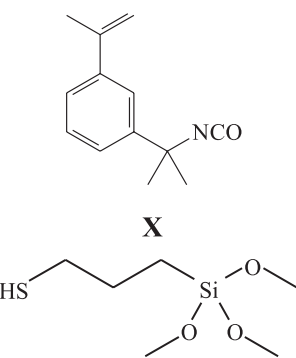

XII components used in the synthesis are found in the final product with no wastes and no intermediate separation processes.

An interesting mechanistic aspect related to siloxanes as potential cellulose grafting moieties arose when our group became involved in their use. It was found ${ }^{[21]}$ that, contrary to previous shaky claims about their reactivity, the Si-OR function does not react with the cellulose hydroxy groups. On the other hand, partially hydrolysed and oligomerised siloxanes, bearing therefore some $\mathrm{Si}-\mathrm{OH}$ groups, do condense with the cellulose $\mathrm{OH}$ counterparts, but even then, high temperatures are necessary to promote this reaction.

\section{The use of planar stiff molecules}

Contrary to the previous strategy, the molecules used here bear two identical reactive moieties, but since they are stiff and planar, their condensation with the cellulose $\mathrm{OH}$ groups, under the heterogeneous experimental conditions applied here, is limited to only one of them, so that the other is left for the subsequent coupling with the matrix monomers or polymers ${ }^{[22-24]}$. This approach is suitable for matrices formed by polycondensation reactions, e.g., epoxy resins, polyurethanes, and polyesters. Molecules XIII and XIV are examples of the structures used.<smiles>O=c1oc(=O)c2cc3c(=O)oc(=O)c3cc12</smiles>

XIII<smiles>O=CNc1ccc([N+](=O)[O-])cc1</smiles>

XIV
The exploitation of this type of modification consisted in carrying out, once more, the processing of the composite material

Table 4. Surface energy of additive-free tracing paper before and after simple and double grafting.

\begin{tabular}{|c|c|c|c|c|c|}
\hline \multicolumn{2}{|c|}{ Grafting } & \multicolumn{3}{|c|}{ Surface energy, $\mathrm{mJ} / \mathrm{m}^{2}$} & \multirow{2}{*}{ Reference } \\
\hline First & Second & $\gamma^{\mathrm{D}}$ & $\gamma^{P}$ & $\gamma^{\mathrm{T}}$ & \\
\hline None & None & 29.4 & 20.0 & 49.4 & {$[16]$} \\
\hline$X$ & None & 42.7 & 0.3 & 43.0 & {$[20]$} \\
\hline VIII & None & 36.7 & 0.8 & 38.5 & {$[20]$} \\
\hline $\mathrm{X}$ & Styrene & 30.9 & 0.8 & 31.7 & {$[20]$} \\
\hline $\mathrm{X}$ & MMA & 44.6 & 0.1 & 44.7 & {$[20]$} \\
\hline VIII & Styrene & 30.9 & 0.8 & 31.7 & {$[20]$} \\
\hline VIII & MMA & 39.1 & 0.1 & 39.2 & [20] \\
\hline IX & None & 33.3 & 9.2 & 43.5 & {$[17]$} \\
\hline IX & Epoxy & 37.9 & 0.8 & 38.7 & {$[17]$} \\
\hline XI & None & 46.9 & 0.1 & 47.0 & [17] \\
\hline XI & MMA & 24.9 & 1.3 & 26.2 & {$[17]$} \\
\hline XI & Styrene & 36.6 & 0.1 & 36.7 & [17] \\
\hline XII & None & 32.0 & 4.0 & 36.0 & {$[17]$} \\
\hline XII & MMA & 40.3 & 2.3 & 42.6 & {$[17]$} \\
\hline XII & Epoxy & 43.5 & 0.8 & 44.3 & [17] \\
\hline
\end{tabular}


Table 5. Weight gain of treated wood as a function of experimental conditions ${ }^{[24]}$.

\begin{tabular}{ccccccc}
\hline $\begin{array}{c}\text { Grafted } \\
\text { molecule }\end{array}$ & $\begin{array}{c}\text { Temperature } \\
\left({ }^{\circ} \mathbf{C}\right)\end{array}$ & $\begin{array}{c}\text { XIII/OH or } \\
\text { XIV/OH ratio }\end{array}$ & Medium & Catalyst & $\begin{array}{c}\text { Reaction time } \\
(\mathbf{h})\end{array}$ & $\begin{array}{c}\text { Weight gain } \\
(\%)\end{array}$ \\
\hline & 70 & $1 / 1$ & DMF & DMAP & 72 & 27 \\
& 70 & $5 / 1$ & DMF & DMAP & 72 & 28 \\
XIII & $10 / 1$ & DMF & DMAP & 72 & 22 \\
& 80 & $1 / 1$ & DMF & DMAP & 24 & 14 \\
& 10 & $10 / 1$ & THF & DMAP & 48 & 2 \\
& $10 / 1$ & DMF & DMAP & 48 & 22 \\
\hline & $1 / 1$ & THF & DBTD & 24 & 8 \\
XIV & 70 & $1 / 1$ & THF & DBTD & 72 & 14 \\
& 70 & $1 / 1$ & Py & None & 24 & 12 \\
\hline
\end{tabular}

DBTD: dibutyltin dilaurate; DMAP: 4-dimethyamino pyridine;

Py: pyridine; DMF: dimethylformamide; THF: tetrahydrofuran

through a one-pot double operation, viz. (i) the modification of the surface of the fibres, carried out using the matrix monomer(s) as the reaction medium, followed by (ii) polycondensation reactions in which the unreacted function participates in the polymer growth, thus giving rise to continuous covalent links between fibres and matrix. The success of this strategy was confirmed by the very large fibre weight gains measured after the composite was extracted to remove all polymers, which had not been covalently linked to the fibre surface ${ }^{[22,24]}$.

The approach was also extended to the chemical modification of bulk wood in order to improve its resistance to biodegradation ${ }^{[24]}$. XIII and XIV were again used, but now one of their reactive functions was made to condense with the $\mathrm{OH}$ groups of the wood macromolecules (cellulose, lignin, hemicelluloses) and the other to append biocide structures, thus giving rise to a high resistance to fungi. Table 5 gives some experimental conditions and results related to the first reaction in this specific context. The weight gains refer to the amount of reagent covalently grafted to the wood sample, i.e., after extracting all the unreacted agent. Note that in this study, wood-swelling media were used to favour the diffusion of XII and XIV into its structure.

The success of the second reaction, viz., the attachment of biocide molecules, was also proven by the failure to extract them after their introduction into the wood activated with XIII or XIV and by specific tests proving the highly enhanced resistance of the ensuing materials to various fungal attacks ${ }^{[24]}$.

\section{Reaction with organometallics}

To the best of our knowledge, we were the first to report the reaction of the surface cellulose $\mathrm{OH}$ groups with organometallic compounds, such as triethylaluminium ${ }^{[25]}$. This approach follows the same working hypotheses discussed above, but here the second coupling of the remaining metalto-carbon (Mt-C) bond(s) takes place with molecular or

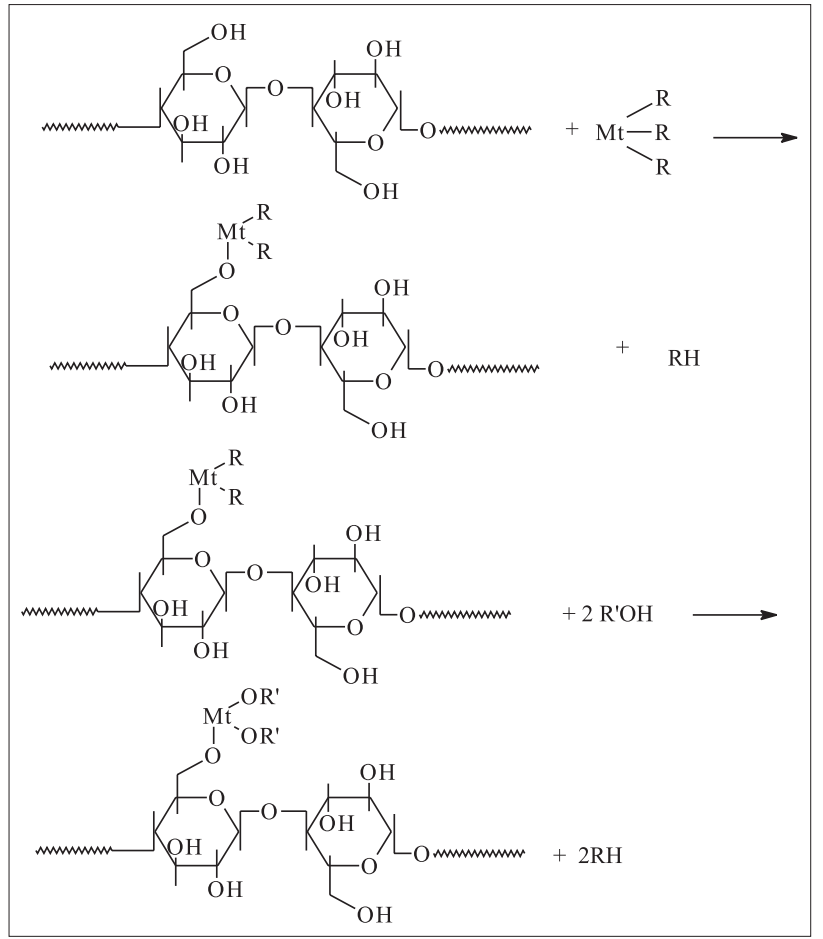

Scheme 1. Example of the mechanisms associated with the treatment of cellulose fibres with organometallic compounds, followed by a second reaction with an alcohol. $\mathrm{Mt}=\mathrm{Al}, \mathrm{B}$.

macromolecular reagents carrying suitable moieties, like $\mathrm{OH}$ and $\mathrm{NH}_{2}$. Scheme 1 illustrates the principle of the strategy with only one Mt-C being involved in the reaction with cellulose. It is however quite possible that, even in heterogenous conditions, two of these bonds might react, but certainly not the three of them, for obvious steric limitations.

Table 6 reports the most relevant results obtained in this field and demonstrates the occurrence of both grafting reactions, because of the appearance of $\mathrm{Al}, \mathrm{B}, \mathrm{N}, \mathrm{Cl}$ atoms 
Table 6. Elemental analyses and surface energies of different lignocellulosic substrates before and after simple and/or double grafting with organometallics ${ }^{[25]}$.

\begin{tabular}{|c|c|c|c|c|c|c|c|c|c|}
\hline \multirow{2}{*}{ Substrate } & \multicolumn{2}{|c|}{ Grafting } & \multicolumn{7}{|c|}{ Elemental analyses } \\
\hline & First reagent & Second reagent & C & $\mathbf{O}$ & $\mathbf{H}$ & Al & B & $\mathbf{N}$ & Cl \\
\hline Avicel & $\mathrm{AlEt}_{3}$ & None & 42.7 & 49.3 & 6.3 & 0.91 & - & - & - \\
\hline Pinewood & $\mathrm{AlEt}_{3}$ & None & 43.8 & 48.5 & 6.0 & 1.69 & - & - & - \\
\hline Pinewood & $\mathrm{BEt}_{3}$ & None & 47.3 & 46.5 & 6.1 & - & 0.03 & - & - \\
\hline Hemp fibres & $\mathrm{BEt}_{3}$ & None & 43.2 & 49.0 & 6.2 & - & 0.05 & - & - \\
\hline Avicel & $\mathrm{AlEt}_{3}$ & Acrylonitrile & 42.1 & 47.1 & 6.1 & 1.66 & - & 3.03 & - \\
\hline Avicel & $\mathrm{BEt}_{3}$ & $\mathrm{ClCH}_{2}-\mathrm{CH}(\mathrm{OH})-\mathrm{CH}_{2} \mathrm{Cl}$ & 43.3 & 48.5 & 6.3 & - & 0.01 & - & 1.65 \\
\hline Pinewood & $\mathrm{AlEt}_{3}$ & Dicyanodiamide & 45.3 & 47.2 & 6.2 & 1.04 & - & 0.27 & - \\
\hline \multirow[t]{3}{*}{ Pinewood } & $\mathrm{BEt}_{3}$ & Dicyanodiamide & 46.4 & 45.2 & 6.2 & - & 0.09 & 0.11 & - \\
\hline & & & \multicolumn{7}{|c|}{ Surface energy, $\mathbf{m J} / \mathbf{m}^{2}$} \\
\hline & & & \multicolumn{2}{|c|}{$\gamma^{\mathrm{D}}$} & \multicolumn{3}{|c|}{$\gamma^{\mathrm{P}}$} & \multicolumn{2}{|l|}{$\boldsymbol{\gamma}^{\mathrm{T}}$} \\
\hline \multirow[t]{2}{*}{ Substrate } & None & None & \multicolumn{2}{|c|}{$30-35$} & \multicolumn{3}{|c|}{$15-25$} & \multicolumn{2}{|l|}{$45-60$} \\
\hline & $\mathrm{AlEt}_{3}$ & 1-heptanol & \multicolumn{2}{|c|}{29.0} & \multicolumn{3}{|c|}{8.1} & \multicolumn{2}{|l|}{37.1} \\
\hline \multirow{3}{*}{ Tracing paper } & $\mathrm{BEt}_{3}$ & 4-aminobenzonitrile & \multicolumn{2}{|c|}{31.0} & \multicolumn{3}{|c|}{15.5} & \multicolumn{2}{|l|}{46.5} \\
\hline & $\mathrm{BEt}_{3}$ & PFPEO & \multicolumn{2}{|c|}{21.0} & \multicolumn{3}{|c|}{7.5} & \multicolumn{2}{|l|}{28.5} \\
\hline & $\mathrm{AlEt}_{3}$ & PFPEO & \multicolumn{2}{|c|}{5.8} & \multicolumn{3}{|c|}{1.5} & \multicolumn{2}{|l|}{7.3} \\
\hline
\end{tabular}

PFPEO: $\alpha$-hydroxy-perfluoropolyethylene oxide.

coming from the grafting agents of the first and/or the second steps and the drastic decrease of the polar component of the surface of cellulose, when the second reagent bore perfluoroalkane moieties.

Further evidence of the success of these reactions was obtained from XPS (Al, B and N peaks) and FTIR spectra (particularly the presence of the characteristic $\mathrm{CN}$ peak at $\sim 2200 \mathrm{~cm}^{-1}$ after the second reaction with dicyanodiamide and extraction to remove its unreacted excess).

As expected, triethylaluminium was found to be much more reactive toward the cellulose $\mathrm{OH}$ groups than its boron counterpart, as shown in Table 6 by the much lower incorporation of boron atoms after the first reaction and by the less drastic decrease in the polar contribution to the surface energy after the second reaction with PFPEO.

The use of $\mathrm{AlEt}_{3}$ followed by the introduction of perfluorated oligomers through the condensation between the remaining $\mathrm{Al}-\mathrm{C}$ bonds and the terminal $\mathrm{OH}$ group of PFPEO (Table 6) and extraction of the unbound reagent, gave rise to a cellulose surface bearing an extremely high hydrophobic character, with a total surface energy even lower than that of polytetrafluoroethylene.

\section{Conclusions}

The modification of the surface of cellulose fibres with the aim of using them in composite materials can be carried out following a variety of procedures and leads to interesting possibilities both in terms of the type of moieties that can be appended and the ensuing surface properties. The most promising approaches are those capable of giving rise to continuous covalent bonds between the cellulose surface and the macromolecular matrix, because they optimise the mechanical properties of the corresponding composites and protect them from water absorption.

A radically different way of rendering the surface of cellulose fibres more compatible with non-polar polymeric matrices was recently explored ${ }^{[26]}$. It called upon the formation of a polymer sleeve around the fibres through the admicellar incorporation of a monomer. Although the ensuing modified surface did not contain chemical links between the cellulose and the polymer sleeve, a good compatibilisation was insured by the surfactant used to generate the admicelles. The other advantage of this technique is that the modifications are carried out in an aqueous medium.

\section{References}

1. Eichhorn, S. J.; Baillie, C. A.; Zafeiropoulos, N.; Mwaikambo, L. Y.; Ansell, M. P.; Dufresne, A.; Entwistle, K. M.; Herraro-Franco, P. J.; Escamilla, G. C.; Groom, L. ; Hughes, M.; Hill, C.; Rials, T. G. \& Wild, P. M. - J. Materials Sci. 36, 2107 (2001).

2. Eco-Composites, a special issue of: Composite Sci. Technol. 
2004, 63, pp. 112, collection of 14 publications all dedicated to Cellulose-based composite materials.

3. Mohanty, A. K.; Misra, M. \& Hinrichsen, G. - Macromolecular Mater. Eng. 2000, 276/277, 1.

4. Gassan, J. \& Bledzki, A. K. - Prog. Polym. Sci. 24, 221 (1999).

5. Lu, J. Z.; Wu, Q. \& McNabb Jr., H. S. - Wood Fibre Sci., $32,88(2000)$

6. Gauthier, R.; Joly, C.; Coupas, A. C.; Gauthier, H. \& Escoubes, M. - Polymer Composites, 19, 287 (1998).

7. Souza Lima, M. M. \& Borsali, R. - Macromol. Rapid Comm., 25, 771 (2004).

8. Katz, S.D. \& Gray, G. - Svensk Papperstidning, 8, 226 (1980).

9. Belgacem, M. N.; Blayo A. \& Gandini, A. - J. Colloid Interface Sci., 182, 431 (1996).

10. Belgacem, M. N.; Czeremuszkin, G.; Sapieha, S. \& Gandini, A. - Cellulose, 2, 145 (1995).

11. Belgacem, M. N. \& Gandini, A. - Composite Interface, 12, 41 (2005).

12. Felix, J.; Gatenholm, P.; Schreiber, H. P. - J. Appl. Polymer Sci., 51, 285 (1994).

13. Shen, W. ; Yao, W.; Li, M. \& Parker, I. - Appita J., 51, 147 (1998).
14. Quilin, D. T.; Caulfield, D. F.; Koutsky, J. A. - Mat. Res. Soc. Symp. Proc., 266, 113 (1992).

15. Felix, J.; Gatenholm, P. - J. Appl. Polym. Sci., 50, 699 (1993).

16. Trejo-O’Reilly, J. A.; Cavaillé, J. Y.; Belgacem, M. N.; Gandini, A. - J. Adhesion, 67, 359 (1998).

17. Ahdelmouleh, M.; Boufi, S.; Ben Salah, A.; Belgacem, M. N. \& Gandini, A. - Intern. J. Adhesion Adhesives, 24, 43 (2004).

18. Matuana, L. M.; Balatinecz, J. J.; Park, C. B. \& Sodhi, R. N. S. - Wood Sci. Technol., 33, 259 (1999).

19. Kazayawoko, M.; Balatinecz, J. J. \& Sodhi, R. N. S. Wood Sci. Technol., 33, 359 (1999).

20. Botaro, V. \& Gandini, A. - Cellulose, 5, 65 (1998).

21. Castellano, M.; Fabbri, P.; Gandini, A. \& Belgacem, M. N. - J. Colloid Interface Sci., 273, 505 (2004).

22. Gandini, A.; Botaro, V. R.; Zeno, E. \& Bach, S. - Polym. Intern., 50, 7 (2001).

23. Borges, J. P.; Godinho, M. H.; Belgacem, M. N. \& Martins, A.F. - Composite Interface, 8, 233 (2001).

24. Bach, S.; Belgacem, M. N. \& Gandini, A. - Holzforchung, 59, 389 (2005).

25. Fabbri, P.; Champon, G.; Castellano, M.; Belgacem, M.N. \& Gandini, A. - Polvm. Intern., 53, 7 (2004).

26. Boufi, S. \& Gandini, A. - Cellulose, 8, 303 (2001). 